\title{
Opt In Versus Opt Out: A Free-Entry Analysis of Privacy Policies*
}

\author{
Jan Bouckaert ${ }^{\dagger}$ and Hans Degryse ${ }^{\ddagger}$
}

September 25, 2006

\begin{abstract}
There is much debate on how the flow of information between firms should be organized, and whether existing privacy laws should be amended. We offer a welfare comparison of the three main current policies towards consumer privacy - anonymity, opt in, and opt out within a two-period model of localized competition. We show that when consumers find it too costly to opt in or opt out, privacy policies shape firms' ability to collect and use customer information, and affect their pricing strategy and entry decision differently. The free-entry analysis reveals that social welfare is non-monotonic in the degree of privacy protection. Opt out is the socially preferred privacy policy while opt in socially underperforms anonymity. Consumers never opt out and choose to opt in only when its cost is sufficiently low. Only when opting in is cost-free do the opt-in and opt-out privacy policies coincide.
\end{abstract}

Keywords: privacy, price discrimination, monopolistic competition, welfare

JEL classification: D11

\footnotetext{
${ }^{*}$ The authors thank Jay Pil Choi and seminar participants at the University of Oslo, UAB Barcelona, the 2005 ESSFM meetings, the 2006 CESIfo Applied Micro Conference, WEISS2006, ESAM2006, and EARIE2006 for stimulating comments. We gratefully acknowledge financial support from FWO-Flanders, the Research Council of the University of Leuven, NOI2003 of the University of Antwerp, and NWO-The Netherlands. Hans Degryse holds the TILEC-AFM Chair on Financial Regulation.

${ }^{\dagger}$ University of Antwerp, Department of Economics, Prinsstraat 13, B-2000 Antwerp, Belgium. jan.bouckaert@ua.ac.be

${ }^{\ddagger}$ CentER - Tilburg University, TILEC, K.U. Leuven and CESIfo, PO Box 90153 NL-5000 LE Tilburg, The Netherlands. H.Degryse@uvt.nl
} 


\section{Introduction}

Advances in information technology have introduced unprecedented possibilities of collecting, storing, transmitting, and analyzing personal information. For example, consumers' purchases at supermarkets, internet stores, and transactions at financial institutions provide firms with a wealth of internally collected personal information on disposable income, family size, age, and other personal identifying data that determine their purchasing behavior. Many businesses use this personal information for commercial purposes and segment their markets into specific customer categories. Moreover, firms often rely on marketed consumer data obtained externally from third parties that collect information on consumers' preferences.

At the same time, the collection, use, and dissemination of personal information have introduced privacy concerns. There is much debate on how the flow of information within and between firms should be organized, and whether existing privacy laws should be amended. According to Stigler (1980), privacy "connotes the restriction of the collection or use of information about a person or corporation; the information in question "belongs" to the individual." This is also what Posner (1981), in defining privacy, refers to as "concealment of information." In this paper, we deal with this meaning of privacy in that privacy policies may shape information regarding a customer's willingness to pay. ${ }^{1}$

The literature on the economics of privacy as developed by Hirshleifer (1980), Stigler (1980), and Posner (1981) argues that in a perfectly competitive world different property rights about ownership of information do not affect the efficient amount of information flow. Stigler (1980) concludes that in voluntary transactions, and provided the conditions of competition are satisfied, there is no reason to protect any one party. Given the legal environment of privacy protection, an efficient amount of information flow will take place. Still, legislators in many countries have dealt differently with privacy concerns in recent decades. Staten and Cate (2003) observe that "the concept that consumers should have the legal right to exercise some degree of choice over commercial use of personal information has become an accepted principle underpinning public policy toward privacy in the United States. However, the form in which that choice must be offered is far from settled" (p. 748). Staten and Cate (2003) argue that the form of

\footnotetext{
${ }^{1}$ Posner (1981) also considers "peace and quiet" and "freedom and autonomy" as two other definitions of privacy. Privacy has not only been studied from an economic perspective but also by other disciplines such as law or social psychology (see Hui and Png (2006) for a recent overview). While these other disciplines study individuals' concerns about privacy invasion and how government should address these, economists typically focus on how consumer information affects social efficiency.
} 
privacy policies differently impacts consumers and businesses because of the transaction costs involved in exercising the legal right to the commercial use of personal consumer information. The contribution of our paper is to identify the welfare effects of different privacy policies in a model with localized competition when consumers incur transaction costs in exercising their legal right to manage their own privacy. While the literature on privacy is vast and growing, there is little theoretical analysis on firms' strategic interactions and the welfare implications of specific privacy policies. We model this research question by comparing three different privacy policies that impose legal restrictions on the handling of personal consumer information.

The first privacy policy is an "opt-out" system. Under opt out, a firm that "intends to share non-public customer information with third parties ... must give consumers an opportunity to deny them permission to do so, or opt out" (Lacker (2002)). Firms can share that information with third parties when the consumer does not object to the use of this non-public or personal information. ${ }^{2}$ In the US, in those industries where the law currently requires that consumers be given a choice, opt out is the privacy policy most commonly used. Examples where the opt-out system applies include the 1999 Gramm-Leach-Bliley Act, the 2000 Fair Credit Reporting Act, or the 2000 Telephone Consumer Protection Act. Under these Acts, firms must provide the consumer with the possibility of opting out when they plan to share personal information.

The second privacy policy is an "opt-in" system. Under opt in, firms have "to obtain a consumer's explicit consent before sharing personal information about them" (Lacker (2002)). Opt in permits the use of personal information within the organization but requires the consumer's explicit consent before personal information can be disclosed to third parties outside the organization. ${ }^{3}$ Interestingly, many states in the US have adopted or are considering regulatory

\footnotetext{
${ }^{2}$ Not all firms offer the same level of detail when sharing information. For example, Adobe Systems Inc. online privacy policy states that "[y]our personal information is also used to track customer preferences and keep you informed about product upgrades, special offers, and other products and services of Adobe and selected third parties unless you have opted not to receive such communications or such communications are prohibited by law." In another instance, only aggregated information is shared with third parties. For example, the New York Times writes in its online privacy policy "[w]e also use demographic and preference information to allow advertising banners on our Web site to be targeted, in aggregate, to the users for whom they are most pertinent. This means that users see advertising that is most likely to interest them, and advertisers send their messages to people who are most likely to be receptive, improving both the viewer's experience and the effectiveness of the ads." Finally, Google's information sharing policy is even more aggregated since "[w]e may share with third parties certain pieces of aggregated, non-personal information, such as the number of users who searched for a particular term, for example, or how many users clicked on a particular advertisement. Such information does not identify you individually."

${ }^{3}$ Staten and Cate (2003) distinguish between "Third-Party Sharing Opt-In" and "Affiliate Sharing Opt-In."
} 
actions regarding the Gramm-Leach-Bliley Act in favor of the stricter privacy opt-in standard for sharing information with third parties. In the European Union, the opt-in system underlies the 1995 European Parliament and Council Directive 95/46/EC. The European Union Data Protection Directive of 1995 provides consumers in the EU member states with protections that emphasize the opt-in as opposed to the opt-out model.

Finally, the third privacy policy can be considered as a benchmark case that guarantees anonymity. ${ }^{4}$ With anonymity, all information collection or storage is prohibited, even within a firm. The implication then is that firms cannot use information to segment customers.

Both the opt-in and opt-out regimes allocate the property rights over personal information to the consumer. When the consumer does not incur any costs in opting in or opting out, these two regimes provide firms with equal access to customer information. For example, if consumers find it beneficial to protect their privacy, they will exercise their option under the opt out privacy policy, but will not do so under opt in. The opposite holds when consumers find it beneficial to release their personal information. However, Staten and Cate (2003) report low exercise rates for both the opt-out and opt-in systems, with generally fewer than $10 \%$ of consumers exercising their option. ${ }^{5}$ These low numbers suggest that consumers find it costly to exercise their option. When opting in or out becomes too costly, the two privacy policies no longer coincide and differently influence firms' access to detailed customer information. In particular, when consumers find it too costly to opt out, personal information about consumers flows unrestrictedly in the economy, and firms can therefore rely on marketed personal information about potential or existing customers to set prices. When consumers find it too costly to opt in, the opt-in system effectively prevents firms from disseminating information about their customers and consequently there will not be a market for personal customer information. That is, when no consumer opts in, new entering firms cannot base their strategic decisions on consumer information obtained from third parties. Firms, however, are allowed to store information internally, and consequently can use the information they obtain over the course of a customer relationship in their pricing decisions. In sum, when consumers find it costly to exercise their option, public

Both variants require opt-in consent before information can be disclosed to third parties. The distinction is that the second puts more restrictions on what can be disclosed to whom.

${ }^{4}$ This is often labelled as "blanket opt-in" (see Staten and Cate (2003)).

${ }^{5}$ Staten and Cate (2003) also cite the case of U.S. West which conducted an affirmative consent trial. The company asked its customers for permission to analyze their calling patterns, but a direct mailing resulted only in a response rate of 5 to $11 \%$. Eventually, U.S. West decided that opt in was not a profitable business model as the subsequent telemarketing test resulted in a prohibitive cost of $\$ 29$ to $\$ 34$ per positive response. 
policy towards privacy affects the quality of firms' access to better and more detailed customer information (see also Armstrong (2006)). Finally, when consumers do not exercise their option, opt out results in the lowest degree of privacy protection as personal information is marketed, opt in offers an intermediate degree of protection as personal information flows only within a firm, and anonymity obviously provides the highest degree of protection.

This paper studies the welfare implications of three different privacy policies - opt in, opt out, and anonymity - employing a two-period version of the Salop (1979) address model of localized competition. This model allows us to study welfare when public policy towards privacy determines (i) the quality of firms' access to customer information; (ii) firms' ability to practice different forms of price discrimination; and (iii) firms' entry decisions. We assume that consumers decide where to buy based on the firms' current and expected future prices, firms' locations, and their own preferences. In our model, the different privacy policies shape the strategic decisions of firms since competitive interactions - prices and entry decisions - are determined by the flow of information. In particular, when consumers find it too costly to exercise their option under the opt-in regime, there is not any marketed personal information about potential or existing customers available. As a result, firms rely only on internally stored personal consumer information stemming from their past customers' purchasing habits. Firms, then, learn about consumers' brand preferences only by first building up a customer base, and practice behaviorbased price discrimination as developed in Fudenberg and Tirole (2000). When consumers find it too costly to exercise their option under the opt-out regime, firms have access to marketed data on potential customers and are then able to immediately segment consumers by practicing thirddegree price discrimination. Finally, under the anonymity regime firms cannot rely either on market-based or on internally stored personal consumer information for their pricing decisions. As a result, they resort to uniform pricing. Our free-entry analysis reveals that the opt-out regime produces better welfare results than the anonymity regime, which in its turn is better than the opt-in regime. Therefore, from a social welfare point of view, it matters whether opt out or opt in is adopted as the privacy standard.

Opt out performs better than anonymity, a result determined by the following trade-off. On the one hand, with opt out and for a given number of firms, suppliers serve some consumers with a low preference for their brand; this results in higher "transportation costs" compared to anonymity where inefficient allocation does not take place. On the other hand, opt out results in "all-out" competition relative to anonymity in that the available information sharpens competition for a given number of firms. Consequently, fewer firms enter with opt out than with 
anonymity. The overall effect is such that total welfare increases more with opt out than with anonymity. Although some consumers are not served by their most nearby supplier, increased competition sufficiently reduces excessive entry to enhance total welfare.

In contrast to anonymity, opt in reduces total welfare. Restricting the use of personal information on past purchasing behavior to within a firm leads to lower welfare results than completely banning the flow of information within and across firms. This result stems from the competitive interactions in the two periods. First, note that for a given number of firms, first-period competition with opt in results in higher first-period prices relative to a model with anonymity. The reasoning is that first-period competition with opt in is also determined by the anticipated firm's second-period pricing behavior, making first-period demand less elastic. The opt-in and anonymity regimes result in consumers being served by their most preferred supplier in the first period. Thus higher first-period profits with opt in augment excessive entry. Second, opt in implies that firms use internally collected information in the second period. This results in (1) all-out competition relative to the anonymity regime and (2) inefficient allocation as some consumers are served by a non-nearby supplier. The overall effect is that the lower first-period competition leading to additional entry and the inefficient second-period allocation dominate the impact of all-out second-period competition. The conclusion then is that opt in leads to lower welfare than anonymity. Thus, when consumers find it too costly to exercise their option, welfare conclusions crucially hinge on privacy policies that determine the flow of information.

Furthermore, we also look at the incentives for consumers to exercise their option to opt in or opt out. We find that all consumers opt in only when its cost is sufficiently low. The reasoning is that prices are lower when personal information is marketed. All consumers exercise their option when the decrease in price outweighs the cost of opting in. Consumers never want to use their option to opt out, as prices would go up by preventing personal information from being marketed.

Our model relates to the literature on behavior-based price discrimination. Recently, Taylor (2004) studied the dynamic strategic pricing behavior of a monopoly ("firm 1") when there is a market for customer information. Consumers are heterogenous and their private valuations for firm 1's goods are positively correlated with other goods offered by another monopoly "firm 2." A consumer's purchasing decision at firm 1 is therefore valuable to firm 2. Taylor examines an anonymity regime in which the sale of customer information is not possible, and a disclosure regime in which firm 1 may compile and sell its customer list to firm 2 which uses it to price discriminate. When consumers are myopic, firm 1 may from time to time charge high prices in 
order to elicit information about its customers' willingness to pay. Welfare critically depends on whether average prices are high or low. When consumers anticipate the selling of their purchasing behavior, they may strategically refuse to buy from firm 1 when it is charging high prices in order to get a lower price at firm 2. This strategic customer behavior reduces the value of a customer list and may force firms to price low. When consumers anticipate the selling of a customer list, a firm might like to commit not to sell its customer list. ${ }^{6}$ This may be interpreted as firms favoring "opt in."

In a similar vein, Acquisti and Varian (2005) analyze a monopolist's optimal intertemporal pricing strategy. They show that when enhanced services can be offered to previous customers, the selling firm will find it optimal to condition its prices on consumers' purchasing history. Acquisti and Varian show that when competing firms offer enhanced services to returning consumers it always pays for firms to condition their prices on consumers' purchasing history. Consumers who prize this personalized service will remain with their current provider as they will not be offered the enhanced service when switching to another provider. Taylor (2004) and Acquisti and Varian (2005) mainly concentrate on monopoly or oligopoly behavior with or without the sale of consumer information. Our paper, in contrast, looks at the competitive and welfare effects of different privacy policies in a two-period model of free entry.

As in Fudenberg and Tirole (2000), our paper studies two-period competition where firms can price discriminate in the second period between their own previous customers and other customers. $^{7}$ Each firm charges a high price to its previous customers (its strong market) and a low price to rivals' first-period customers (its weak market). Since one firm's weak market is the other firm's strong market, the firms' best-responses are asymmetric and second-period competition drives prices down as in Corts (1998). While these papers consider duopoly, we are interested in the extent to which the different forms of price discrimination that result from the three privacy policies affect welfare under free entry. In their literature review Armstrong (2006) and Stole (2005) remark that free entry typically results in too much entry from a social welfare point of view. When price discrimination increases profits, excessive entry worsens. In contrast, price discrimination lessens excessive entry when it reduces oligopoly profits. ${ }^{8}$ Liu and Serfes (2005) consider a one-period free-entry analysis where the quality of marketed consumer

\footnotetext{
${ }^{6}$ See also Calzolari and Pavan (2005).

${ }^{7}$ Villas-Boas (1999) considers an overlapping generations model where firms recognize their own customers but cannot distinguish new entering consumers from others who previously bought from rivals.

${ }^{8}$ For another thorough review on the recent developments of price discrimination, see Villas-Boas and Fudenberg (2005).
} 
information determines the degree of segmentation. They vary the degree of possible consumer segmentation, and find that moderate segmentation results in the most efficient free-entry outcome. Our paper, in contrast, studies how privacy protection (i) shapes a firm's ability to collect and use customer information, (ii) bears on a firm's intertemporal behavior-based pricing strategy, and (iii) changes welfare through firms' entry decisions. Our two-period free-entry analysis reveals that social welfare is non-monotonic in the degree of privacy protection. Opt out is the socially preferred privacy policy while opt in socially underperforms anonymity.

Section 2 develops the analysis of the three privacy policies, while Section 3 offers the main results of our paper by comparing the three privacy policies. Section 4 provides a discussion and conclusion.

\section{Privacy Policies}

Consider a market where a continuum of consumers with unit mass is uniformly distributed along a circle with circumference one. Consumers live for two periods, have constant preferences over time, and have a unit demand for non-durable goods in each period. Consumers' willingness to pay $v$ is high enough so as to guarantee that all consumers buy in each period. A consumer located at distance $x$ from firm $i$ (with $i=1, \ldots, N$ ) derives utility

$$
v-t x-p_{\tau}^{i}
$$

from consuming one unit of goods in period $\tau$ (with $\tau=1,2$ ) and purchased from firm $i$, where $t$ denotes the linear transportation cost per unit of distance and $p_{\tau}^{i}$ the price paid at firm $i .^{9}$ With the exception of transportation costs, switching between sellers is cost-free, and there is no possibility of arbitrage between consumers.

Firms and consumers have a common discount factor $0 \leq \delta<1$. Prior to first-period competition, $N$ firms decide to enter the market for both periods and locate equidistantly along the circle. The cost of entry is $(1+\delta) F$ and is sunk up front at $\tau=1$. This entry cost structure allows for a direct comparison with a one-period Salop model where the entry cost equals $F$. Thus firms commit to enter for both periods before competition starts. Firms start to compete for consumers at $\tau=1$. Depending on the privacy policy, firms do or do not have information about consumers prior to first-period competition. In period $\tau=2$ firms compete again for

\footnotetext{
${ }^{9}$ We assume that the available gross surplus $v$ does not depend on the different privacy policies. Consumer surplus, however, may suffer from giving up privacy.
} 
consumers. The information available about their customer base or future clientele is again determined by the privacy policy.

Firms compete in prices during each period and cannot commit to future prices; that is, we do not consider long-term contracts. Prices are set simultaneously in both periods. In contrast to Taylor (2004) our model is not set up to analyze the market for consumer information. Instead, our objective is to investigate the implications of three different privacy policies on interfirm competition and their consequences for welfare. To study these effects in isolation, we assume that firms can access information, when available, at zero cost.

\subsection{Opt in}

With opt in, consumers must explicitly consent to third-party use of personal data. In line with empirical evidence already referred to in the Introduction, we make the simplifying assumption that all consumers face substantial transaction costs such that they do not opt in. As a result, all consumers do not permit personal information about their purchasing patterns in related industries to become publicly available. Firms therefore lack specific information about consumers before competing in the first period and before setting prices. Firms then need to resort to uniform pricing in the first period. However, the opt-in regime allows firms to store information about their customers internally and to use this information in their second-period pricing strategies. That is, firms are able to practice purchase history-based pricing in the second period. We assume that a firm can store information about whether a consumer patronized its shop in period one. The implication then is that firms in the second period can set different prices to those offered to their first-period consumers and other consumers. This is optimal as first-period consumers have revealed they have a "higher preference" for that firm, and are willing to pay higher prices for products from that firm. We first treat the oligopolistic setting based on the duopoly analysis of Fudenberg and Tirole (2000). Then we turn to free entry and social welfare, respectively.

\subsubsection{Oligopoly}

Consider first an oligopoly situation with $N$ firms that are located symmetrically on the circle. The circle can then be subdivided into $N$ neighborhoods. Neighborhood $i j$ is the neighborhood where firms $i$ and $j$ (with $i, j=1, \ldots, N$ and $i \neq j$ ) compete with each other (so effectively $j=i+1$ for all $i=1, \ldots, N-1$, and $j=1$ for $i=N)$. The distance between firms $i$ and $j$ equals $1 / N$ for any neighborhood. As our analysis concentrates on symmetric situations, let 
$b$ denote the position of the indifferent consumer in the first period located in between $i$ and $j$, with $0 \leq b \leq 1 / N$. Denote by $p_{2}^{i j}$ firm $i$ 's second-period price offered to customers of firm $j$ 's first-period market. Denote by $x^{\prime}$ the position of the consumer in the second period who is indifferent between switching from $i$ to $j$ or staying with $i$. Similarly, $y^{\prime}$ is the position of the consumer in the second period who is indifferent between switching from $j$ to $i$ or staying with $j$. It should be clear that $x^{\prime} \leq b$ and $y^{\prime} \geq b$.

We start the analysis with second-period competition. Firm $i$ has served the market segment $0 \leq b \leq 1 / N$ in the first period, while firm $j$ served $1 / N-b$. The position of the second-period customer $x^{\prime}$, indifferent between switching from $i$ to $j$, is such that

$$
p_{2}^{i i}+t x^{\prime}=p_{2}^{j i}+t\left(\frac{1}{N}-x^{\prime}\right)
$$

and the position of the second-period customer $y^{\prime}$ indifferent between switching from $j$ to $i$, equals

$$
p_{2}^{j j}+t\left(\frac{1}{N}-y^{\prime}\right)=p_{2}^{i j}+t y^{\prime} .
$$

Firm $i$ maximizes its second-period profits in the neighborhood $i j$

$$
\Pi_{2}^{i}\left(p_{2}^{i i}, p_{2}^{i j}\right) \equiv p_{2}^{i i} x^{\prime}+p_{2}^{i j}\left(y^{\prime}-b\right)
$$

while firm $j$ maximizes

$$
\Pi_{2}^{j}\left(p_{2}^{j j}, p_{2}^{j i}\right) \equiv p_{2}^{j j}\left(\frac{1}{N}-y^{\prime}\right)+p_{2}^{j i}\left(b-x^{\prime}\right) .
$$

The first-order conditions are

$$
\begin{aligned}
p_{2}^{i i} & =0.5\left(p_{2}^{j i}+\frac{t}{N}\right) \\
p_{2}^{i j} & =0.5\left(p_{2}^{j j}+\frac{t}{N}-2 t b\right) \\
p_{2}^{j j} & =0.5\left(p_{2}^{i j}+\frac{t}{N}\right) \\
p_{2}^{j i} & =0.5\left(p_{2}^{i i}+2 t b-\frac{t}{N}\right) .
\end{aligned}
$$

A symmetric solution for the second period yields

$$
\begin{aligned}
p_{2}^{i i} & =t\left(2 b+\frac{1}{N}\right) / 3 \\
p_{2}^{i j} & =t\left(\frac{3}{N}-4 b\right) / 3 \\
p_{2}^{j j} & =t\left(\frac{3}{N}-2 b\right) / 3 \\
p_{2}^{j i} & =t\left(4 b-\frac{1}{N}\right) / 3
\end{aligned}
$$


Note that the first-period market share $b$ shapes second-period competition. In particular, a greater $b$ relaxes competition in $i$ 's first-period market but sharpens competition in $j$ 's firstperiod market. We now turn to first-period competition, which determines the first-period market share. ${ }^{10}$ In the first period, the indifferent forward-looking consumer anticipates that in the second period the "poaching firm" will offer attractive prices. That is the indifferent consumer anticipates that it will be beneficial in the second period to visit the rival's shop. Given the discount rate $\delta$, the indifferent first-period consumer located at $b$ is characterized by

$$
p_{1}^{i}+t b+\delta\left[p_{2}^{j i}+t\left(\frac{1}{N}-b\right)\right]=p_{1}^{j}+t\left(\frac{1}{N}-b\right)+\delta\left(p_{2}^{i j}+t b\right)
$$

or

$$
b=\frac{p_{1}^{j}-p_{1}^{i}+\delta\left(p_{2}^{i j}-p_{2}^{j i}\right)+\frac{t}{N}(1-\delta)}{2 t(1-\delta)} .
$$

In words, the consumer with position $b$ is indifferent between buying in the first period from firm $i$ at price $p_{1}^{i}$ and switching to $j$ in the second period, or buying from $j$ in the first period at price $p_{1}^{j}$ and switching to firm $i$ in period two.

The discounted total profits look like

$$
\Pi^{i}\left(p_{1}^{i}, p_{1}^{j}\right) \equiv p_{1}^{i} b+\delta\left[\Pi_{2}^{i}\left(p_{2}^{i i}, p_{2}^{i j}\right)\right]
$$

for firm $i$ and

$$
\Pi^{j}\left(p_{1}^{i}, p_{1}^{j}\right) \equiv p_{1}^{j}\left(\frac{1}{N}-b\right)+\delta\left[\Pi_{2}^{j}\left(p_{2}^{j j}, p_{2}^{j i}\right)\right]
$$

for firm $j$. The first-order conditions are

$$
\begin{aligned}
& p_{1}^{i}=\frac{\frac{t\left(\delta^{2}+6 \delta+9\right)}{N}+p_{1}^{j}(9-7 \delta)}{2(9-2 \delta)} \\
& p_{1}^{j}=\frac{\frac{t\left(\delta^{2}+6 \delta+9\right)}{N}+p_{1}^{i}(9-7 \delta)}{2(9-2 \delta)} .
\end{aligned}
$$

A symmetric solution yields

$$
p_{1}^{i}=p_{1}^{j}=\frac{t(\delta+3)}{3 N} .
$$

The symmetric equilibrium then implies $b=\frac{1}{2 N}$, resulting in

$$
\begin{aligned}
& p_{2}^{i i}=p_{2}^{j j}=\frac{2 t}{3 N} \\
& p_{2}^{i j}=p_{2}^{j i}=\frac{t}{3 N} .
\end{aligned}
$$

\footnotetext{
${ }^{10}$ The analysis assumes that firms attract market share only from neighborhoods adjacent to their own locations. We return to this at the end of this section.
} 
Comparison of prices reveals that

$$
p_{1}^{i}=p_{1}^{j}>p_{2}^{i i}=p_{2}^{j j}>p_{2}^{i j}=p_{2}^{j i} .
$$

Thus, first-period prices exceed second-period prices. Moreover first-period prices are higher than in a standard Salop model with uniform pricing, where prices would equal $t / N$. The reasoning stems from the lower elasticity of first-period demand relative to the static Salop model. This lower elasticity relaxes first-period competition.

We also find that

$$
\begin{aligned}
x^{\prime} & =\frac{1}{3 N} \\
y^{\prime} & =\frac{2}{3 N},
\end{aligned}
$$

implying that one third of all consumers are served by their less preferred supplier in the second period, whereas all consumers are served by their most preferred supplier in the first period. ${ }^{11}$ Firm $i$ and $j$ 's discounted total equilibrium profits in neighborhood $i j$ look like

$$
\Pi^{i}=\Pi^{j}=\frac{t(9+8 \delta)}{18 N^{2}} .
$$

This analysis leads to similar results as in Fudenberg and Tirole (2000). Note, however, that our oligopoly framework allows for more than two firms. We should therefore consider whether firms cannot engage in profitable deviations by setting "supercompetitive prices" - prices with which a firm captures all customers on both sides of the closest neigbouring brand - as described in Salop (1979). Such a price discontinuously shifts the deviator's demand outwards. While in Salop's model such deviations are unprofitable, our two-period framework may render such a deviation worthwhile. The reasoning is that although a deviation in the first period results in lower first-period profits, it may substantially relax competition in the next period. It turns out that such a deviation becomes unprofitable (i) with sufficiently convex transportation costs as the discontinuous shift in the demand curve from setting a supercompetitive price no longer exists; (ii) when assuming that $\delta$ is sufficiently low (i.e. $\delta<9 / 28$ ); ${ }^{12}$ or (iii) when consumers

\footnotetext{
${ }^{11}$ The condition that all consumers buy in the first period is guaranteed when $v \geq$ $\max [t / 2 N+t(\delta+3) / 3 N, 2 t(2+\delta) / 3 N]$. Otherwise, some consumers to the left of $x^{\prime}$ and to the right of $y^{\prime}$ would strategically refrain from purchasing in period 1. By doing so, they could benefit from the lowest second-period prices at the closest shop.

${ }^{12}$ To see this, start from the candidate equilibrium prices $p_{1}^{i}=p_{1}^{j}=t(\delta+3) / 3 N$. Given these prices, firm $i$ can attract a first-period market share of $3 / N$ by lowering its price with $t / N$ and setting a first-period supercompetitive
} 
only consider patronizing the two closest shops, for example because it is too costly to examine prices in non-neigbouring firms. Note that the duopoly setting of Fudenberg and Tirole (2000) implies that consumers can only choose between the two neighboring firms, and therefore the duopoly setting should not deal with supercompetitive prices. Our analysis will concentrate on the competitive equilibrium resulting in Eq. (1) as this allows us to focus on free entry and to compare our results with opt out and anonymity.

\subsubsection{Free Entry}

We employ the results from the oligopoly case in order to study free entry. Recall that firms simultaneously decide whether to enter or not, and that entry costs are $(1+\delta) F$. After entry has occurred, the firms play the two-period game as analyzed in the previous subsection. As prices with opt in decline from period 1 to period 2, additional entry in the second period of the game (at a cost $F$ ) is unprofitable. Our free-entry equilibrium of the two-period model is therefore entry-proof in the second period.

As firm $i$ attracts consumers from its two nearby neighborhoods, profits double those of Eq. (1). Each firm's discounted total variable profits with opt in equal

$$
\Pi_{I N}^{i}=\frac{t(9+8 \delta)}{9 N^{2}} .
$$

The free-entry condition with opt in amounts to

$$
\Pi_{I N}^{i}-(1+\delta) F=0 .
$$

The equilibrium number of firms $N_{I N}^{f}$ then becomes

$$
N_{I N}^{f}=\sqrt{\frac{t(9+8 \delta)}{9(1+\delta) F}} .
$$

How to evaluate welfare with opt in? Welfare losses with opt in under free-entry become

$$
\begin{aligned}
W_{I N}^{f} & =2 N_{I N}^{f} t\left[\int_{0}^{1 / 2 N_{I N}^{f}} \mathbf{x} d \mathbf{x}+\delta\left(\int_{0}^{1 / 3 N_{I N}^{f}} \mathbf{x} d \mathbf{x}+\int_{1 / 3 N_{I N}^{f}}^{1 / 2 N_{I N}^{f}}\left(1 / N_{I N}^{f}-\mathbf{x}\right) d \mathbf{x}\right)\right]+N_{I N}^{f}(1+\delta) F \\
& =\frac{(45+43 \delta)}{12} \sqrt{\frac{t F(1+\delta)}{(9+8 \delta)}} .
\end{aligned}
$$

price equal to $\delta / 3 N$. As a result, its first-period profits will equal $\delta t / N^{2}$. Under the assumption that the nonadjacent firms do not adopt their pricing strategies, the second-period prices and market shares are $t / N$ and $1 / N$, respectively, as its adjacent firms will not have served any consumers in the first period. Its discounted profits, then, are $2 \delta t / N^{2}$. This expression is larger then Eq. (1) whenever $\delta>9 / 28$. Note that if the non-adjacent firms were also to adjust their prices, they would have an incentive to become more aggressive. Therefore the condition $\delta<9 / 28$ is a sufficient condition but not a necessary condition. 
The first term between the square brackets reflects the first-period transportation costs since consumers visit their most preferred supplier. The second term captures the discounted secondperiod transportation costs. In the second period some inefficient allocation takes place: consumers in the middle of each neighborhood visit a "more distant" firm to take advantage of the more attractive second-period price. The third term reflects total entry costs.

\subsubsection{Social Planner}

How many firms will a social planner allow? And what are the associated welfare losses? Suppose that the social planner controls the (maximum) number of firms entering the market but cannot control their oligopolistic behavior once they have entered. It follows that firms will implement "purchase-history based price discrimination", since it is dominant for firms to price discriminate in period two. Entry still implies a social cost $(1+\delta) F$. The welfare losses to be minimized by the social planner are

$$
W_{I N}=2 n t\left[\int_{0}^{1 / 2 n} \mathbf{x} d \mathbf{x}+\delta\left(\int_{0}^{1 / 3 n} \mathbf{x} d \mathbf{x}+\int_{1 / 3 n}^{1 / 2 n}(1 / n-\mathbf{x}) d \mathbf{x}\right)\right]+n(1+\delta) F,
$$

with $n$ being the number of firms to be determined by the social planner. As with free entry, the first term between the square brackets reflects the first-period transportation costs, while the second term captures the discounted second-period transportation costs. Minimizing this expression yields the socially optimal number of firms with opt in $n_{I N}^{*}$,

$$
n_{I N}^{*}=\sqrt{\frac{t(9+11 \delta)}{36(1+\delta) F}} .
$$

This yields the following welfare losses

$$
W_{I N}^{*}=\sqrt{\frac{t F(11 \delta+9)(1+\delta)}{9}} .
$$

Notice that excessive entry takes place as

$$
N_{I N}^{f}>n_{I N}^{*}
$$

That is, the social planner restricts entry. We will further elaborate on these results when comparing the different privacy policies in Section 3. 


\subsection{Opt out}

The opt-out system gives consumers the option to prohibit the sharing of their personal information. We model that consumers do not exercise the option to opt out as they may face substantial transaction costs, are unaware of this option or may not find it beneficial to exercise it. This is in line with actuality since only a very few consumers exercise this option. As a result, consumers reveal personal information through their past purchases at other firms. Consequently, each firm obtains marketed consumer information about consumers' brand preferences before first-period competition takes place. In particular, every firm is informed about whether a consumer's location is "closer to its shop" or not, as in Bester and Petrakis (1996). ${ }^{13}$ This assumption (i) maintains the essential characteristics of opt out as entrants have access to customer information, (ii) buys us an easy comparison with opt in, and (iii) allows us to analyze the symmetric outcome of a standard product differentiation model. Information on customer location allows firms to practice third-degree price discrimination in the first period between nearby consumers and others. This is optimal as consumers located nearby have a "higher preference" for that firm but show a lower preference for firms further away. While under opt out firms have access to a market for customer information, they could additionally compile customer information themselves. However, to highlight the differences we treat opt out as if firms rely on market-based customer information only and opt in as if firms have no access to such a source. Before discussing competition in this setting it is important to remark that first-period and second-period competition are independent of each other. The reasoning is that firms use only exogenously available information in their pricing decisions. The first-period market share does not affect second-period competition; each period can therefore be studied separately, and prices and market shares will be identical across the two periods.

\subsubsection{Oligopoly}

Assume that $N$ firms enter the market. Firms are located symmetrically on the circle. As before, the distance between adjacent firms $i$ and $j$ in neigborhood $i j$ equals $1 / N$. The informational environment is such that firms $i$ and $j$ know whether or not a consumer is located in between 0

\footnotetext{
${ }^{13}$ Note that this assumption implies that each firm's information set differs when the number of firms $N>2$. In other words, consumers known to firm $i$ as living closest to its shop differ from $j$ 's. An alternative assumption is that firms have identical information about every consumer's "brand ordering". In a localized model of competition, however, these two assumptions produce identical results. The reasoning is that serving consumers from non-adjacent neigborhoods turns out to be unprofitable.
} 
and $1 /(2 N)$, and in between $1 /(2 N)$ and $1 / N$. Firms $i$ and $j$ then will price discriminate between consumers located in their hinterland and those located further away. Denote by $p^{i j}$ firm $i$ 's price offered to customers "located further away" (closer to firm $j$ ). Denote by $x$ the position of the consumer in $i$ 's hinterland who is indifferent between proximate firm $i$ and the more distant firm $j$. Similarly, $y$ is the position of the consumer in $j$ 's hinterland who is indifferent between the proximate firm $j$ and the more distant firm $i$. It should be clear that $x \leq 1 /(2 N)$ and $y \geq 1 /(2 N)$.

The position of the customer $x$ in $i$ 's hinterland, indifferent between firm $i$ and $j$, is such that

$$
p_{\tau}^{i i}+t x=p_{\tau}^{j i}+t\left(\frac{1}{N}-x\right),
$$

where $p_{\tau}^{i i}$ is the price charged in period $\tau$ by firm $i$ to a customer located in its hinterland. Similarly $p_{\tau}^{j i}$ is the price charged in period $\tau$ by firm $j$ to a customer in firm $i$ 's hinterland. In a similar fashion, the position of customer $y$ in $j$ 's hinterland, indifferent between $j$ and $i$, equals

$$
p_{\tau}^{j j}+t\left(\frac{1}{N}-y\right)=p_{\tau}^{j j}+t y .
$$

Firm $i$ maximizes its profits in the neighborhood $i j$ during period $\tau$

$$
\Pi_{\tau}^{i}\left(p_{\tau}^{i i}, p_{\tau}^{i j}\right) \equiv p_{\tau}^{i i} x+p_{\tau}^{i j}\left(y-\frac{1}{2 N}\right) .
$$

The (necessary and sufficient) first-order conditions are

$$
\begin{aligned}
p_{\tau}^{i i} & =0.5\left(p_{\tau}^{j i}+\frac{t}{N}\right) \\
p_{\tau}^{i j} & =0.5\left(p_{\tau}^{j j}\right) \\
p_{\tau}^{j j} & =0.5\left(p_{\tau}^{i j}+\frac{t}{N}\right) \\
p_{\tau}^{j i} & =0.5\left(p_{\tau}^{i i}\right) .
\end{aligned}
$$

A symmetric solution implies

$$
\begin{aligned}
p_{\tau}^{i i} & =p_{\tau}^{j j}=\frac{2 t}{3 N} \\
p_{\tau}^{i j} & =p_{\tau}^{j i}=\frac{t}{3 N}
\end{aligned}
$$

Firm $i$ and $j$ 's equilibrium per period profits in neighborhood $i j$ look like

$$
\Pi_{\tau}^{i}=\Pi_{\tau}^{j}=\frac{5 t}{18 N^{2}} .
$$


As market shares in all periods $\tau$ are identical, total discounted profits per firm (net of fixed costs) in neighborhood $i j$ become

$$
\Pi^{i}=\Pi^{j}=\frac{5 t(1+\delta)}{18 N^{2}}
$$

\subsubsection{Free Entry}

What happens with free entry? Taking into account that firms realize profits in two adjacent neighborhoods and incur fixed entry costs, the per firm discounted profits become

$$
\Pi^{i}=\frac{5 t(1+\delta)}{9 N^{2}}-(1+\delta) F
$$

The free-entry equilibrium number of firms with opt out, $N_{O U T}^{f}$, becomes

$$
N_{\text {OUT }}^{f}=\sqrt{\frac{5 t}{9 F}} .
$$

Discounted welfare losses $W_{\text {OUT }}^{f}$ can be computed as the sum of (i) current and discounted "transportation" costs, and (ii) entry costs. Welfare losses then boil down to

$$
\begin{aligned}
W_{O U T}^{f} & \left.=2(1+\delta) N_{O U T}^{f} t\left[\int_{0}^{1 / 3 N_{O U T}^{f}} \mathbf{x} d \mathbf{x}+\int_{1 / 3 N_{O U T}^{f}}^{1 / 2 N_{O U T}^{f}}\left(1 / N_{O U T}^{f}-\mathbf{x}\right) d \mathbf{x}\right)\right]+N_{O U T}^{f}(1+\delta) F \\
& =\frac{31}{60}(1+\delta) \sqrt{5 t F} .
\end{aligned}
$$

The first term between the square brackets represents the customers travelling to the closest firm whereas the second term within those brackets represents the customers visiting a more distant supplier (as it offers a lower price). The last term represents the entry costs.

\subsubsection{Social Planner}

What is the optimal number of firms from a social welfare point of view with opt out? Suppose that the social planner controls the (maximum) number of firms entering the market but cannot control their oligopolistic pricing behavior once they have entered. As it is a dominant strategy for firms to price discriminate between "close" and "distant" consumers, welfare losses to be minimized are

$$
\left.W_{\text {OUT }}=2 n(1+\delta) t\left[\int_{0}^{1 / 3 n} \mathbf{x} d \mathbf{x}+\int_{1 / 3 n}^{1 / 2 n}(1 / n-\mathbf{x}) d \mathbf{x}\right)\right]+n F(1+\delta) .
$$


Solving the first-order condition yields the optimal number of firms, $n_{O U T}^{*}$, with

$$
n_{\text {OUT }}^{*}=\sqrt{\frac{11 t}{36 F}}
$$

Substituting $n_{\text {OUT }}^{*}$ into $W_{O U T}$ yields as welfare losses

$$
W_{O U T}^{*}=(1+\delta) \sqrt{\frac{11 t F}{9}}
$$

\subsection{Anonymity}

The third system we consider is anonymity. With anonymity, detailed personal consumer information cannot be used. Firms therefore cannot access specific customer information, and are not allowed to store such information and use it in the second period. Firms then need to practice uniform pricing in both periods. It is clear that first- and second-period competition are not linked. The reasoning is that first-period market shares do not affect second-period competition. Therefore we can address first- and second-period competition independently of each other.

\subsubsection{Oligopoly}

Assume that $N$ firms entered the market before competition starts. Firms are located symmetrically on the circle. As before, the distance between firms $i$ and $j$ in neighborhood $i j$ equals $1 / N$. As firms offer only one price, there is only one indifferent consumer located at $a$ such that

$$
p_{\tau}^{i}+t a=p_{\tau}^{j}+t\left(\frac{1}{N}-a\right)
$$

where $p^{i}$ and $p^{j}$ are the prices charged by firms $i$ and $j$ in period $\tau$, respectively.

Firms $i$ and $j$ maximize their profits during period $\tau$ in the neighborhood $i j$

$$
\begin{aligned}
\Pi_{\tau}^{i}\left(p^{i}, p^{j}\right) & \equiv p_{\tau}^{i} a \\
\Pi_{\tau}^{j}\left(p^{j}, p^{i}\right) & \equiv p_{\tau}^{j}(1-a) .
\end{aligned}
$$

The (necessary and sufficient) first-order conditions are

$$
\begin{aligned}
& p_{\tau}^{i}=0.5\left(p_{\tau}^{j}+\frac{t}{N}\right) \\
& p_{\tau}^{j}=0.5\left(p_{\tau}^{i}+\frac{t}{N}\right) .
\end{aligned}
$$

A symmetric solution implies

$$
p_{\tau}^{i}=p_{\tau}^{j}=\frac{t}{N} .
$$


The variable profits during period $\tau$ on neighborhood $i j$ become

$$
\Pi_{\tau}^{i}=\Pi_{\tau}^{j}=\frac{t}{2 N^{2}}
$$

\subsubsection{Free Entry}

The free entry number of firms with anonymity $N_{A N}^{f}$ is determined by the following zero profit condition

$$
N_{A N}^{f}=(1+\delta) \frac{t}{N^{2}}-(1+\delta) F=0 .
$$

Recall that each firm obtains profits on two neighborhoods and in two periods. Firms also incur fixed entry costs. The free-entry equilibrium number of firms $N_{A N}^{f}$ then becomes

$$
N_{A N}^{f}=\sqrt{\frac{t}{F}}
$$

Welfare losses with anonymity $W_{A N}^{f}$ become

$$
\begin{aligned}
W_{A N}^{f} & =(1+\delta) \frac{t}{4 N_{A N}^{f}}+N_{A N}^{f}(1+\delta) F \\
& =\frac{5}{4}(1+\delta) \sqrt{t F} .
\end{aligned}
$$

With anonymity, all consumers are served by their most preferred supplier. This is reflected in the first term of the welfare losses as the average consumer travels $\frac{1}{4 N_{A N}^{f}}$. The second term represents the fixed entry costs.

\subsubsection{Social Planner}

With anonymity, a social planner minimizes the following welfare losses

$$
W_{A N}=(1+\delta) \frac{t}{4 n}+n(1+\delta) F .
$$

Minimization yields $n_{A N}^{*}$ the socially optimal number of firms

$$
n_{A N}^{*}=\sqrt{\frac{t}{4 F}} .
$$

Plugging this $n_{A N}^{*}$ into the welfare losses yields

$$
W_{A N}^{*}=(1+\delta) \sqrt{F t} .
$$




\section{A Welfare Comparison of Privacy Policies}

This section compares the results of the three different privacy policies with regard to the degree of privacy protection each affords. As mentioned in the Introduction, opt out provides consumers with the lowest degree of privacy protection, opt in offers an intermediate degree, and anonymity results in the highest degree.

We first discuss the extent to which the different privacy policies result in excessive entry. Next we discuss whether less excessive entry always leads to higher welfare by providing a welfare comparison of free entry and the social planner. We also report on the extent to which the oligopoly findings align with those under free entry. Finally, we discuss consumers' behavior when their costs in exercising the option for privacy protection are low. The proofs of the Propositions directly follow from comparing the findings in Section 2 and are omitted.

The analysis of the welfare losses for the three different privacy policies under free entry and the social planner yields the first Proposition.

Proposition 1: All privacy policies result in excessive entry. Excessive entry increases unambiguously according to the degree of privacy protection. Formally, we find that

$$
N_{A N}^{f}>N_{I N}^{f}>N_{O U T}^{f}>n_{O U T}^{*}>n_{I N}^{*}>n_{A N}^{*}
$$

Not surprisingly the anonymity regime yields excessive entry as it coincides with Salop's (1979) results; hence $N_{A N}^{f}>n_{A N}^{*}$. The other two privacy policies allow for price discrimination and lead to all-out competition (see Corts (1998)). Under both policies, firms make lower profits and this dampens the excessive entry problem. More specifically, under the opt-out regime, allout competition occurs in both periods. With opt in, although first-period prices outweigh the prices of the anonymity regime, second-period prices are sufficiently low to result in overall all-out competition. Consequently, the discounted price $\bar{P}^{f}$ an average consumer pays ranks as

$$
\bar{P}_{A N}^{f}>\bar{P}_{I N}^{f}>\bar{P}_{O U T}^{f}
$$

for the three different regimes. This explains the free-entry ordering $N_{A N}^{f}>N_{I N}^{f}>N_{O U T}^{f}$.

The degree of privacy protection also determines the socially optimal number of firms. The opt-in regime results in an inefficient allocation of consumers in the second period as some consumers choose a more distant supplier. The social planner corrects for this consumer behavior 
by increasing the number of firms as this reduces the cost of inefficient allocation. Under the optout regime this inefficient allocation occurs in both periods. This explains $n_{O U T}^{*}>n_{I N}^{*}>n_{A N}^{*}$. This shows that the degree of excessive entry increases unambiguously according to the degree of privacy protection. Finally, note that lowering the degree of privacy protection only mitigates the excessive entry problem but does not make it disappear, a result that further corroborates the findings of Norman and Thisse (1996) and Bhaskar and To (2004) who also study the effect of price discrimination on the free entry number of firms. ${ }^{14}$

Proposition 2: Privacy protection matters for social welfare. The free-entry analysis shows that social welfare is non-monotonic in the degree of privacy protection. Opt out is the preferred privacy policy while opt in underperforms the anonymity regime. The social planner unambiguously prefers more privacy protection. Formally, we find that welfare losses rank as

$$
W_{I N}^{f}>W_{A N}^{f}>W_{O U T}^{f}>W_{O U T}^{*}>W_{I N}^{*}>W_{A N}^{*}
$$

The different privacy policies influence social welfare as they determine the number of entrants and the degree of efficient consumer allocation. The free-entry analysis reveals that opt out socially outperforms anonymity. This insight stems from the following trade-off. On the one hand, some consumers prefer to purchase from a more distant supplier. This inefficient allocation does not occur in the anonymity regime where all consumers patronize the closest shop, lowering social welfare. On the other hand, a significantly lower number of firms enter with opt out, as has been shown in Proposition 1, thereby improving social welfare. The analysis shows that the second effect dominates the first. Thus, although some consumers are not served by their most preferred supplier, opt out sufficiently mitigates excessive entry to enhance total welfare.

In contrast, opt in reduces total welfare by comparison to anonymity. Two opposing effects explain this finding. Opt in results in somewhat less excessive entry as opposed to anonymity, and while this is certainly to the benefit of social welfare, it is not enough to outweigh the inefficient allocation of consumers in the second period. The overall effect is that opt in reduces social welfare, thus illustrating that opt in is not a convex combination of the anonymity and opt-out regimes. Under opt in, firms strategically adopt an intertemporal pricing scheme where first-period prices are higher than under anonymity and second-period prices lower than under

\footnotetext{
${ }^{14}$ In a somewhat different model where consumers can be sorted according to their willingness to pay, Borenstein (1985) predicts that the number of firms in a free-entry model increases with price discrimination. Similarly, Holmes (1989) finds that when firms' best-responses are symmetric, profits will increase with third-degree price discrimination.
} 
opt out. Thus, welfare changes in a non-monotonic way according to the degree of privacy protection. Under free entry, moving from the highest degree of privacy protection (anonymity) towards an intermediate level of privacy protection (opt in) is socially harmful. However, the lowest degree of privacy protection (opt out) is welfare improving as compared to anonymity. Policymakers should, therefore, be in favor of a market for customer information.

Finally, when the social planner can control the number of firms as well as the degree of privacy protection, it should favor the highest degree of privacy protection through anonymity as this generates efficient consumer allocation.

Corollary: The degree of excessive entry is not a sufficient statistic to make welfare judgments.

Proposition 1 reveals that under opt in and opt out the equilibrium number of firms is less excessive by comparison with anonymity. Proposition 2 shows that welfare with opt out socially outperforms anonymity. However, opt in underperforms socially compared to anonymity. Therefore, our analysis shows that welfare does not necessarily increase when the degree of excess entry diminishes.

Proposition 3: The welfare ranking of privacy policies differs between oligopoly and free entry.

From Proposition 2 we know that welfare changes non-monotonically according to the degree of privacy protection. In contrast, social welfare increases unambiguously with privacy protection in oligopoly. The reasoning is that greater privacy protection increases the efficiency of consumer allocation. The opt-out regime nicely illustrates how the welfare consequences of free entry and oligopoly can be opposite. While opt out is clearly the most preferred privacy policy under free entry, the welfare analysis under oligopoly shows the opposite result. Obviously, this result stems from the fact that the oligopoly analysis takes the number of firms as fixed whereas with free entry the number of firms becomes part of the analysis and is endogenously determined.

Our analysis so far assumes that consumers find it too costly to opt in or to opt out. However, it may be true that in certain industries some consumers experience low or zero costs in exercising their option. We now investigate what happens when consumers face zero costs. Consider first the opt-out privacy policy. A consumer who opts out prevents information about him from being used by firms in setting prices. In our model, consumers have no incentive to opt out even with zero costs. The reasoning is that by opting out, the consumer prevents his personal information from being marketed, with the result that the firm charges him a higher first-period price. As a result, no consumer opts out. In contrast, with opt in and a zero exercising cost, all 
consumers have an incentive to exercise their option. The reasoning is that consumers benefit from all-out competition in the first period, since by opting in a consumer's personal information is marketed. Suppose now that there were a small cost for exercising the option. Opting out now becomes even more unattractive as the customer faces a price increase as well as the cost of opting out. Consumers deciding to opt in, by contrast, weigh the cost of opting in against the higher first-period price from not exercising the option; as long as this cost of exercising the option is sufficiently low, consumers will opt in. The following Proposition, summarizes the previous discussion.

Proposition 4: Consumers only opt in when the cost of exercising the option is sufficiently low. Consumers never opt out.

\section{Discussion and Concluding Remarks}

In this paper we study how public policy towards privacy influences social welfare. The property rights approach to the economics of privacy shows that when the conditions of competitive markets hold, ownership of personal consumer information will not affect the efficient amount of information flow. Two commonly used privacy policies - opt in and opt out - allocate property rights over personal information to the consumer. Under opt out, an important privacy policy in the US, firms have access to marketed personal consumer information when the consumer does not object. Opt in permits the use of personal information inside a firm but requires the consumer's explicit consent before this information can be disclosed to third parties outside the firm. The European Union emphasizes the opt-in model. This paper identifies the welfare effects of opt in and opt out in public policy towards privacy when consumers find it costly to exercise their legal rights to manage their privacy. We investigate this policy issue employing a two-period address model where the privacy policy affects firms' access to personal consumer information.

We find that when consumers find it costly to manage their privacy, these two privacy policies shape social welfare differently. In particular, a privacy policy influences the number of entrants and the degree of efficient consumer allocation. Our free-entry analysis shows that social welfare is non-monotonic, depending on the degree of privacy protection. Opt out is the socially preferred privacy policy. The anonymity benchmark, in which firms cannot rely on any personal consumer information, outperforms opt in. Although the opt-out regime leads 
to inefficient consumer allocation - not all consumers buy from the socially optimal supplieropt out leads to all-out competition compared to anonymity, resulting in less excessive entry. In contrast, opt in exhibits lower total welfare than anonymity. Welfare changes in a nonmonotonic way according to the degree of privacy protection. Putting some restrictions on privacy, as with opt in, is socially more harmful than imposing complete privacy protection, as happens under anonymity. However, the lowest degree of privacy protection (opt out) maximizes social welfare. Policymakers should, therefore, realize that when consumers find the management of their privacy costly, privacy policies matter for social welfare. In particular, our free-entry analysis suggests that opt out is the socially preferred privacy policy when the property rights of personal consumer information are allocated to the consumer and when managing these property rights is costly.

Our free-entry analysis also yields two other results. First, the degree of excessive entry is not a sufficient statistic to draw welfare conclusions. Social welfare is lower with opt in, although excessive entry is mitigated by comparison with anonymity. Competition policy therefore needs to address more than market structure only. Second, welfare results may substantially differ between oligopoly and free entry. To illustrate this point, while it is clear that oligopoly results in inefficient consumer allocation when considering opt out, our free entry analysis reverses this result as all-out competition substantially reduces excess entry.

Our analysis builds on marketed information about whether or not consumers belong to specific consumer segments. Firms, however, may have access to more detailed information than we considered in our analysis. For example, information about consumers could be partitioned into a larger number of market segments as in Liu and Serfes (2005). While their analysis shows that competition increases up to a certain degree of consumer partitioning and decreases thereafter, greater possibilities of engaging in price discrimination as compared to our setting always result in fiercer competition. A more detailed partitioning of consumer information would strengthen the result that opt out is the socially preferred privacy policy. The reasoning is that fiercer price competition further reduces excessive entry and the extent of inefficient consumer allocation.

Finally, we have limited our notion of privacy to Posner's (1981) "concealment of information." Obviously, the other definitions of "peace and quiet" and "freedom and autonomy" referred to by Posner could be incorporated by introducing a value for privacy into consumers' utility functions. Our contribution, however, shows that in a model of localized competition, consumers may benefit from lower prices. Eventually, policy makers must trade lower prices 
for consumers off against the value society attaches to "peace and quiet" and "freedom and autonomy."

\section{$5 \quad$ References}

Acquisti, A., and H. Varian, 2005, Conditioning prices on purchase history, Marketing Science, 24, 3, Summer, 367-381.

Armstrong, M., 2006, Recent developments in the economics of price discrimination, forthcoming in Advances in Economics and Econometrics: Theory and Applications: Ninth World

Congress, eds. Blundell, Newey and Persson, Cambridge University Press.

Bester, H. and E. Petrakis, 1996, Coupons and oligopolistic price discrimination, International Journal of Industrial Organization, 14, 227-242.

Bhaskar V. and T. To, 2004, Is perfect price discrimination really efficient? An analysis of free entry, RAND Journal of Economics, 35,4, 762-776.

Borenstein, S., 1985, Price discrimination in free-entry markets, RAND Journal of Economics, 16, 3, Autumn, 380-397.

Calzolari, G. and A. Pavan, 2006, On the optimality of privacy in sequential contracting, Journal of Economic Theory, 130, 1, September, 168-204.

Corts, K.S., 1998, Third-degree price discrimination in oligopoly: All-out competition and strategic commitment, RAND Journal of Economics, Vol. 29, 2, Summer, 306-323.

Fudenberg, D. and J. Tirole, 2000, Customer poaching and brand switching, RAND Journal of Economics, Vol. 31, 4, Winter, 634-657.

Fudenberg, D. and J. M. Villas-Boas, 2005, Behavior-based price discrimination and customer recognition, mimeo.

Hirshleifer, J., 1980, Privacy, its origin, function, and future, Journal of Legal Studies, 9, 649-666.

Hui, K.-L., and I. Png, 2006, The economics of privacy, forthcoming in Handbook of Information Systems and Economics, ed. Terry Hendershott.

Lacker, J., 2002, The economics of financial privacy: To opt out or opt in?, Economic Quarterly, 88, 3, 1-16.

Liu, Q., and K. Serfes, 2005, Imperfect price discrimination, market structure, and efficiency, Canadian Journal of Economics, November, 38, 4, 1191-1203. 
Posner, R., 1981, The economics of privacy, American Economic Review, Papers and Proceedings, 71, 2, 405-409.

Salop, S. C., 1979, Monopolistic competition with outside goods, Bell Journal of Economics, $10,141-156$.

Staten, M. E. and F. H. Cate, 2003, The impact of opt-in privacy rules on retail credit markets: A case study of MBNA, Duke Law Journal, 52, 745-786.

Stigler, G., 1980, An introduction to privacy in economics and politics, Journal of Legal Studies, 9, 623-644.

Stole, L., 2003, Price discrimination in competitive environments, forthcoming in Handbook of Industrial Organization, mimeo.

Taylor, C., 2004, Consumer privacy and the market for customer information, RAND Journal of Economics, 35, 4, 631-650.

Villas-Boas, J.M., 1999, Dynamic competition with customer recognition, RAND Journal of Economics, 30, 604-631. 
Copyright ( 22006 @ the author(s). Discussion papers are in draft form. This discussion paper is distributed for purposes of comment and discussion only. It may not be reproduced without permission of the copyright holder. Copies of working papers are available from the author. 